\title{
1 Ground-Penetrating Radar Monitoring of Concrete at High Temperature
}

2 Francesco LO MONTE ${ }^{1}$, Federico LOMBARDI $^{2}$, Roberto FELICETTI ${ }^{1}$, Maurizio LUALDI $^{1}$

${ }^{1}$ Department of Civil and Environmental Engineering, Politecnico di Milano, Milan (Italy)

${ }^{2}$ Department of Electronic and Electrical Engineering, University College of London, London (UK) e-mails: francesco.lo@polimi.it, f.lombardi@ucl.ac.uk, roberto.felicetti@polimi.it, $\underline{\text { maurizio.lualdi@polimi.it }}$

\section{link to full paper: https://authors.elsevier.com/a/1VKDW301E18hJt}

Keywords: Concrete, drying, fire, Ground-Penetrating Radar, high temperature, pore pressure, spalling, vaporization, water. 


\section{Introduction}

\subsection{Effect of water in concrete at high temperature: fire spalling and shielding capability}

Fire and, more generally, high temperature are extreme loads which need to be considered when strategic buildings and infrastructures are at issue, such as hospitals, tall buildings, nuclear power plants and tunnels. Even though concrete performs fairly well at high temperature, thanks to its low thermal conductivity and incombustibility, adequate fire resistance in structures can be achieved only if attention is paid to mix design, reinforcement arrangement and structural redundancy. In some cases, such as tunnels and nuclear power plants, not only the bearing capacity should be guaranteed, but also the performance regarding specific aspects such as fire- or heat-induced spalling and radiation shielding capability.

Heat-induced spalling is the violent breaking-off of concrete pieces from the exposed face, leading to sectional reduction and direct exposure of the reinforcing bars to the flames, both aspects being detrimental to the overall fire resistance.

Even though structural fire behaviour of tunnels is of concern just in extremely severe scenarios, avoiding spalling is a primary objective, since repair time and cost are critical issues together with the revenue loss because of traffic disruption.

A full understanding of spalling phenomenon, however, is no simple matter because of the presence of different factors such as heating rate, concrete thermo-physical properties degradation, initial moisture content and saturation level, pore pressure and stress (Kalifa et al., 2000; Khoury, 2000 and 2008; Fu and Li, 2010).

As sketched in Fig.1, the phenomenon can be ascribed to the mutual interaction between stress-induced cracking, ensuing from thermal gradients and external loads, and pore pressure rise, due to water vaporization and/or saturation (Khoury, 2000).

Thermal stress is caused by the significant temperature gradients typical of heated insulating materials. 
In particular, compression arises in the exposed hot layers and tension in the cold core, followed by cracking parallel to the exposed face in the former case and orthogonal to the heated face in the latter one. Kinematic incompatibility between aggregate and cement paste, and release of absorbed- and chemically-bound water, as well as cement dehydration, also favour cracking (Fu and $\mathrm{Li}, 2010)$.

Pressure in the pores, on the other hand, is caused by water vaporization and vapour dilation. Pressure gradients cause moisture migration towards both the hot face and the inner core. In the latter case, moisture content can increase also due to vapour condensation, with possible saturation of the pores (Khoury, 2008). Especially in low-porosity concretes, such as High-Performance Concretes - HPC, water saturation in the pores can be attained, with the formation of a region characterized by very low permeability (the so-called moisture clog; Khoury, 2008). Consequently, very high values of pore vapour pressure can develop behind moisture clog (up to $5 \mathrm{MPa}$; Kalifa et al., 2000).

On the contrary in high-porosity concretes, such as Normal-Strength Concrete - NSC, vapour can more easily flow through cement matrix, this reducing the pressure. This is the reason why spalling is a big concern in HPC, together with its higher heat-sensitivity compared to NSC (Felicetti and Gambarova, 1998).

A well-established way to reduce spalling sensitivity is the addition of polypropylene fibre, whose beneficial effect comes from the further porosity induced by fibre melting at 160$170^{\circ} \mathrm{C}$ (Khoury, 2008), accompanied by microcracking in the cement matrix due to thermal dilation of melting fibre (Khoury, 2008) and to the stress intensification around the edges of the melting fibre (Pistol et al., 2014).

In spalling-sensitive structures like tunnels, the quantification of shard detachment via coupled hygro-thermo-mechanical or hygro-thermal numerical models can be useful in the design phase. Such analyses can be performed by means of available numerical codes able to 
simulate heat and (fluids) mass transfer in concrete at high temperature (Gray and Schrefler, 2001; Ichikawa and England, 2004; Tenchev and Purnell, 2005; Davie et al., 2006; Gray and Schrefler, 2007; Gawin et al., 2011a and 2011b).

The main problem for such models is the definition of concrete properties (first of all, porosity and permeability), that can be hardly measured at high temperature. In this case, inverse analysis based on experimental fire tests is the most reliable means for preliminary calibration. Within this context, water front monitoring in lab tests may be very helpful.

Water plays an important role also in the containment shells of nuclear power plants and radioactive waste repositories, thanks to its shielding property against $\alpha, \beta$ and neutron radiation. Consequently, knowing how water front migrates at high temperature is instrumental in assessing the time required by a containment shell to fully dry, as complete drying reduces its shielding capability (Ichikawa and England, 2004; USNRC, 2013).

\subsection{Ground-Penetrating Radar for water front monitoring}

Water front monitoring in concrete at high temperature is a challenging task, since the few techniques able to perform such measurement, as for example Neutron Radiography Imaging - NRI (Weber et al., 2013; Toropovs et al., 2015) and Nuclear Magnetic Resonance - NMR (van der Heijden et al., 2007; Erich et al., 2008; van der Heijden et al., 2011; van der Heijden et al., 2012) are very costly and strongly limit specimen geometry $(100 \times 100 \times 25 \mathrm{~mm}$ for NRI in Toropovs et al., 2015; DxH = 80x100 mm for NMR in van der Heijden et al., 2012).

Another technique able to monitor water content and saturation in concrete is based on Ground-Penetrating Radar - GPR (Laurens et al., 2005; Sbartai et al., 2012; Rodriguez-Abad et al., 2014; Bagnoli et al. 2015).

GPR is a well-known and established non-destructive geophysical technique (Jol, 2008) commonly used in the field of structure inspections and building diagnosis (Lualdi and Lombardi, 2014a; Lualdi and Lombardi, 2014b; Benedetto and Pajewski, 2015), in addition to 
a number of other high resolution subsurface imaging applications. It employs electromagnetic fields for the detection of buried objects and subsurface structures, and for material property characterization (Muller et a., 2016; Daniels, 2004). GPR relies on the principle that electromagnetic waves are reflected and scattered to some extent at boundaries separating different regions in the subsurface (Maierhofer, 2003; Yehia et al., 2014).

103 Reflected and scattered waves are then collected by the receiver.

104 Among all the parameters determining the overall electrical properties, water content is the most significant factor (Sbartai et al., 2006a; Lai et al., 2009). Water content variations produce amplitude changes of GPR data (Laurens et al., 2002; Sbartai et al., 2006b; Klys and Balayssac, 2007), and significant travel time shifts once the changes involve a large portion of 108 the imaged subsurface.

109 The amplitude of the reflections depends on the magnitude of the contrast between two contiguous regions, while the time shifts are caused by water slowing down the

111 electromagnetic wave velocity. As reported in Laurens et al. (2005), the dielectric constant $\varepsilon_{r}$

112 can be increased by more than two times going from dry $\left(\varepsilon_{r, d r y} \approx 4\right)$ to saturated concrete $113\left(\varepsilon_{r, s a t} \geq 8\right)$. An even higher range is reported in IAEA (2002): $\varepsilon_{r, d r y}-\varepsilon_{r, s a t} \approx 4.5-15$.

114 As demonstrated by Laurens et al. (2005), Sbartai et al. (2012), Rodriguez-Abad et al. 115 (2014) and Xiao et al. (2016), the above-mentioned mechanisms make GPR an effective 116 method to characterize water content and transfer in concrete. GPR has also been used for 117 assessing thermal damage in concrete after a fire, as shown in Abraham and Dérobert (2003).

118 In the present study, the primary objective is to detect the water front position in concrete 119 at high temperature, rather than to directly measure the water content. GPR technique has 120 been implemented within a research project at Politecnico di Milano (Lo Monte and Felicetti, 121 2017). Concrete slabs heated at the bottom face have been tested both in unloaded conditions 122 and under biaxial membrane loading, as discussed in the following sections. 


\section{Experimental set-up and mix design}

124

125

126

127

128

129

130

131

132

133

134

135

136

137

138

139

140

141

142

143

144

145

146

147

\subsection{Fire test on concrete slabs}

A test setup has been designed and built at Politecnico di Milano for assessing concrete spalling sensitivity in fire conditions (Lo Monte and Felicetti, 2017). The specimen is a square concrete slab with an $800 \mathrm{~mm}$-side and $100 \mathrm{~mm}$-thickness (Fig.2a), subjected to heating at the bottom face according to the Standard temperature-time curve defined by EC1 (EN 1991-12:2004). During heating, a biaxial membrane load can be applied thanks to 8 hydraulic jacks restrained by a welded steel frame (Fig.2b). The fire load is applied by means of a horizontal furnace provided with a propane burner controlled by an active control system.

In order to protect the hydraulic jacks from high temperature, only the central portion of the slab is heated $(600 \times 600 \mathrm{~mm})$. As shown in Fig.2a, 16 slits have been cut in the peripheral region of the specimen in order to break the mechanical continuity of the external cold rim so as to minimize the confining effect.

During the test, pressure and temperature can be monitored through the thickness via special embedded sensors (see also Felicetti et al., 2017) placed at 10, 20, 30, 40, 50 and $60 \mathrm{~mm}$ from the exposed face (Figs.2c,d).

\subsection{Ground-Penetrating Radar - GPR}

In one of the slabs tested so far, GPR technique has been implemented at the cold face (Fig.2a), aimed at monitoring the water front position during fire exposure. The measurements have been performed by exploiting the reflection of the electromagnetic waves propagating through a continuum, when a sudden change in electric properties occurs (see Fig.3a).

In the present case, the discontinuity is represented by the water front, namely the sharp gradient in water content separating dried and moist concrete (Fig.3a), while no or negligible influence is expected to be introduced by any possible fracturing process. Since, as abovementioned, concrete dielectric constant can increase by more than two times between 
148 dry and saturated concrete, the aim of the present experimental study is to verify if the

149 reflection due to such variation of electric properties allows to detect and monitor water front 150 migration with sufficient accuracy.

151 The equipment is an IDS georadar antenna with a central frequency of $3 \mathrm{GHz}$ (Fig. $3 \mathrm{~b}$ ). The

152 two dipoles are $60 \mathrm{~mm}$-spaced and are oriented orthogonally to the acquisition direction.

153 A series of profiles have been acquired at the cold face of the slab over the same scan line

154 (Fig.2a and Fig.3b) during heating, with an almost constant time separation between 155 subsequent scans. Profiles characteristics are reported in Table 1, while the processing steps 156 (Yilmaz, 2001) applied on the datasets are described in Table 2.

157 The location of the GPR has been studied in order to avoid boundary effects linked to 158 thermal, electromagnetic or stress fields. Temperature and stress distributions have been 159 previously analysed via thermo-mechanical numerical models performed via the finite 160 element code Abaqus, while no disturbance in GPR measurements has been observed during 161 the experimental test due to the presence of the hydraulic jacks (thanks to the distance 162 between the antenna and the actuators, which was larger than $20 \mathrm{~cm}$ ).

163 Preliminarily, the wave velocity has been accurately computed by placing a metallic plate

164 at the bottom face of the slab to plainly detect wave reflection. Time to depth conversion 165 resulted in a velocity of $13.5 \mathrm{~cm} / \mathrm{ns}$, corresponding to a relative dielectric constant of 166 approximately 5 and a vertical radar resolution $\lambda / 4$ of about $1 \mathrm{~cm}$.

\subsection{Concrete mix design and applied load}

168 The tested slab was made of HPC with $400 \mathrm{~kg} / \mathrm{m}^{3}$ of CEM I, $200 \mathrm{~kg} / \mathrm{m}^{3}$ of Ground Granulated

169 Blast Furnace Slag, $1559 \mathrm{~kg} / \mathrm{m}^{3}$ of silico-calcareous aggregates (maximum aggregate size

$17016 \mathrm{~mm}$ ) and water-to-cement ratio equal to 0.36 .

171 Monofilament polypropylene fibre was added (content $=2 \mathrm{~kg} / \mathrm{m}^{3}, \mathrm{~L}=12 \mathrm{~mm} ; \emptyset_{\text {eq }}=$ $17220 \mu \mathrm{m}$; extruded straight fibre treated with a surfactant agent). Membrane load was designed 
173 to induce a constant mean compressive stress of $10 \mathrm{MPa}$, sufficient to avoid any tensile stress

174 throughout the test. To authors' knowledge, this is the first fire test in which water front,

175 temperature and pore pressure are simultaneously monitored under loading in fire conditions.

\section{3. Results and discussion}

177 Results from GPR scans are shown in Fig.4 for different values of fire duration. In each frame

178 the geometrical limits of the slab (top and bottom faces) are indicated (solid triangles), as well

179 as the rising water front position (black dots). The comparison among the accurate repeated

180 GPR surveys reveals travel time shifts and amplitude variations among corresponding

181 reflection events. Beside each frame of Fig.4, the spatial average trace is provided to facilitate

182 the identification of the recorded events. In this way, for each time step, the information is

183 synthesized by a single wave, in which the effects of concrete heterogeneity are minimized.

184 While the amplitude at the top of the slab remains constant throughout the test, a 185 significant blurring appears in the lower part after approximately $20 \mathrm{~min}$ of heating. This is a

186 clear evidence of the presence of a highly absorbing thin layer of water moving from the 187 heated surface towards the cold core of the slab. This effect ensues from the high absorption 188 capability of water that reduces the amount of energy transmitted through the remaining 189 portion of the slab and then collected at the receiver.

190 The migration of the water front, together with the significant temperature rise in the hot 191 layers of the slab, produces a variation in the electrical properties distribution. This appears as 192 a change in the location of the bottom face as shown in the last frame of Fig.4 and highlighted

193 in Fig.5. Considering the initial conditions of the slab, this modification induces an average 194 increase in the velocity of about $10 \%$, corresponding to a decrease of the average relative 195 dielectric constant from 5 to 4 . On the other hand, the thermal effect on the location of the 196 water front is expected to be not significant. This depends on the fact that the region of the slab comprised between the cold face (where GPR is implemented) and the water front, experiences 
198 limited temperatures $\left(\leq 330^{\circ} \mathrm{C}\right.$, see Fig.8). For this thermal range, electric properties should be 199 negligibly influenced by temperature, as demonstrated by the absence of any shift in the 200 location of the bottom face of the slab in the first 50 min of heating.

201 In order to clearly identify the migration of the water front during the test, the spatial average traces of Fig.4 have been arranged in the synthetic radargram shown in Fig.6a.

The horizontal gradient has been then computed by subtracting to each spatial average trace the initial one (corresponding to concrete in virgin conditions), and the result is reported in Fig.6b. The subtraction of repeated GPR surveys produces an image in which the differences among time steps are enhanced, in order to more easily detect hygrally active regions.

In Fig.6 the rise of a high reflective front is clearly detectable, as well as the bottom reflection. The result in terms of water front position as a function of time is finally reported in Fig.7. Once the water front position is known for any given fire duration, it is possible to evaluate the time at which the water front crosses the points where temperature and pressure have been measured, as shown in Fig.8.

The measurements of temperature and pressure as a function of time for the 6 measuring 213 points within the slab thickness are reported in Figs.8a,c, respectively. The coloured dots in 214 the same plots represent the time at which the water front crosses those points. Temperature and pressure profiles in the depth for different values of fire duration are reported in Figs.8b,d, respectively. Also in these plots, coloured dots are used to show the position of the 217 water front at the time step corresponding to each pressure and temperature profile.

218 In Figs.8a,b it can be observed that the water front starts rising at 10 min, when 219 temperature exceeds $200^{\circ} \mathrm{C}$. After $20 \mathrm{~min}$ of heating, the temperature at the water front goes up to $322^{\circ} \mathrm{C}$. Afterward, water front continuously rises, while the corresponding temperature decreases down to about $200^{\circ} \mathrm{C}$ after $110 \mathrm{~min}$. In Figs.8c,d it is clear that the peak pore pressure (both in time and space domains) is reached in correspondence of the water front. 
223 Such result is reasonable, since the highest vapour pressure is expected to develop where 224 evaporation takes place, reaching its maximum value when almost all water is vaporized.

225 The reason why temperature at the water front decreases with time can be found in Fig.9a, 226 where the pressure at the measuring points is plotted as a function of temperature, together 227 with the dots representing the time at which the water front crosses such points. At increasing 228 depths, in fact, pore pressure-temperature rate increases, since the path that vapour has to 229 travel to escape is higher and moisture migration is slower, as schematically described in 230 Fig.9b (adapted from Mindeguia, 2009). Hence, moving towards the core of the slab, pressure 231 development with temperature becomes closer to the vapour pressure saturation curve, which 232 represents the pressure at which water vaporizes at a given temperature when no vapour 233 leakage is allowed. This explains why higher pressure can be reached at lower temperature, 234 for increasing values of water front distance from the heated face.

\section{Concluding remarks}

236 The use of Ground-Penetrating Radar (GPR) for monitoring water front migration in concrete 237 during heating is discussed in the present paper. GPR has been implemented in a fire test 238 based on one-side heated concrete slab, together with the continuous measurement of 239 temperature and pressure along the thickness of the specimen.

240 GPR proves to be able of detecting the water front position during heating with an 241 accuracy comparable to other methods such as Neutron Radiography Imaging and Nuclear 242 Magnetic Resonance. The big advantage of GPR is the possibility to be easily implemented in 243 any concrete member heated on one side, which is the common configuration of fire tests for 244 tunnel lining segments and concrete slabs.

245 The combination of GPR and pressure measurement allows to better characterize the 246 hygro-thermal behaviour of concrete, this being instrumental in investigating spalling 247 mechanisms and radiation shielding capability in case of fire. 
The experimental results highlight that water front cannot be directly related to a particular temperature, while it is evident that pore pressure peaks in both time and space domains are reached in correspondence of water front position. This is probably the first experimental evidence of such behaviour.

Finally, it is worth noting that the most effective approach for the evaluation of fire spalling evolution in concrete is based on the combination between experimental testing and numerical analyses involving the hygro-thermo-mechanical behaviour. For such numerical models, fire tests in which temperature, pressure and water front are monitored represent detailed benchmarks instrumental for the calibration phase. This can be of big help when the design of strategic reinforced-concrete structures and infrastructures is at issue.

\section{Acknowledgments}

259 The Authors are grateful to CTG-Italcementi Group (Bergamo, Italy), for the design of the 260 concrete mix and the preparation of the specimen, and to Fondazione Lombardi Ingegneria 261 (Minusio, Switzerland) for the financial support given to this research project. IDS Georadar 262 Srl is also thanked for providing the Ground-Penetrating Radar equipment. Finally, the 263 authors are grateful to Prof. Pietro G. Gambarova for helping in improving the manuscript.

264 This work is a contribution to COST (European COoperation on Science and Technology) 265 Action TU1208 "Civil Engineering Applications of Ground Penetrating Radar."

\section{References}

267 1. Kalifa P., Menneteau F. D. and QuenardD., 'Spalling and pore pressure in HPC at high temperatures', 268 Cement and Concrete Research 30,pp. 1915-1927, 2000.

$2692 . \quad$ Khoury G.A.,'Effect of fire on concrete and concrete structures', Progress in Structural Engineering and Materials 2, pp. 429-447, 2000.

271 3. KhouryG.A.,'Polypropylene Fibres in Heated Concrete. Part 2: Pressure Relief Mechanisms and Modelling Criteria', Magazine of Concrete Research 60 (3), pp.189-204, 2008. 
273 4. Fu Y. and Li L., 'Study on mechanism of thermal spalling in concrete exposed to elevated temperatures', $274 \quad$ Materials and Structures 44, pp. 361-376, 2010.

275 5. Felicetti R. and Gambarova P. G., 'On the Residual Tensile Properties of High Performance Siliceous 276 Concrete Exposed to High Temperature', Special Volume in honour of Z.P. Bazant's $60^{\text {th }}$ 277 Anniversary, Prague (Czech Republic), March 27-28, Ed. Hermes (Paris), pp. 167-186, 1998.

278 6. Pistol K., Weise F., Meng B. and Diederichs U., "Polypropylene fibres and micro cracking in fire exposed 279 concrete”, Advanced Materials Research, 897, 284-289, 2014..

280 7. Gray W.G. and Schrefler B.A. "Thermodynamic approach to effective stress in partially saturated porous 281 media”, European Journal of Mechanics - A/Solids, 20, pp. 521-538, 2001.

282 8. Ichikawa Y., England G.L. "Prediction of moisture migration and pore pressure build-up in concrete at high 283 temperatures", Nuclear Engineering and Design, 228, pp. 245-259, 2004.

2849 9. Tenchev R., Purnell P. "An application of a damage constitutive model to concrete at high temperature and 285 prediction of spalling”, International Journal of Solids and Structures, 42, pp. 6550-6565, 2005.

10. Davie, C.T., Pearce, C.J., Bicanic, N. "Coupled heat and moisture transport in concrete at elevated

11. Gray W.G. and Schrefler B.A. "Analysis of the solid phase stress tensor in multiphase porous media", International Journal for Numerical and Analytical Methods in Geomechanics, 31, pp. 541-581, 2007.

12. Gawin D., Pesavento P and Schrefler B.A. "What physical phenomena can be neglected when modelling concrete at high temperature? A comparative study. Part 1: Physical phenomena and mathematical model", International Journal of Solids and Structures, 48, pp. 1927-1944, $2011 \mathrm{a}$.

13. Gawin D., Pesavento P. and Schrefler B.A. "What physical phenomena can be neglected when modelling concrete at high temperature? A comparative study. Part 2: Comparison between models", International Journal of Solids and Structures, 48, pp. 1945-1961, 2011b.

14. USNRC. "A Review of the Effects of Radiation on Microstructure and Properties of Concretes Used in Nuclear Power Plants", NUREG/CR-7171, ORNL/TM-2013/263, 2013.

15. Weber B., Wyrzykowski M., Griffa M., Carl S., Lehmann E. and Lura P. "Neutron radiography of heated high-performance mortar", MATEC Web of Conferences, 6, 2013. 
16. Toropovs N., Lo Monte F., Wyrzykowski M., Weber B., Sahmenko G., Vontobel P., Felicetti R. and Lura P., "Real-time measurements of temperature, pressure and moisture profiles in High-Performance Concrete exposed to high temperatures during neutron radiography imaging", Cement and Concrete Research 68, pp. 166-173, 2015.

17. van der Heijden G.H.A., van Bijnen R.M.W., Pel L. and Huinink H.P. "Moisture transport in heated concrete, as studied by NMR, and its consequences for fire spalling", Cement and Concrete Research

18. Erich S.J.F., van Overbeek A.B.M., van der Heijden G.H.A., Pel L., Huinink H.P., Peelen W.H.A. and Vervuurt A.H.J.M. "Validation of FEM models describing moisture transport in heated concrete by Magnetic Resonance Imaging”, HERON Vol. 53, No. 4, 2008.

19. van der HeijdenG.H.A., Huinink H.P., Pel L., KopingaK. "One-dimensional scanning of moisture in

20. van der Heijden G.H.A., Pel L. and Adan O.C.G. "Fire spalling of concrete, as studied by NMR", Cement and Concrete Research 42, 265-271, 2012.

21. Laurens S., Balayssac J. P., Rhazi J., Klysz G. and Arliguie, 'Non-destructive evaluation of concrete moisture by GPR: experimental study and direct modeling', Materials and Structures 38, pp. 827-832, 2005.

22. Sbartai Z. M., Breysse D., Larget M. and Balayssac J. P., 'Combining NDT techniques for improved evaluation of concrete properties, Cem. \& Conc. Comp. 34, pp. 725-733, 2012.

23. Rodriguez-Abad, Martinez-Sala R., Mene J., 'Water penetrability in hardened concrete by GPR' Proc. of $15^{\text {th }}$ Int. Conf. on Ground Penetrating Radar-GPR 2014,June 30-July 4, pp. 862-867, 2014.

24. Bagnoli P., Bonfanti M., Della Vecchia G., Lualdi M. and Sgambi L. "A method to estimate concrete hydraulic conductivity of underground tunnel to assess lining degradation", Tunnelling and Underground Space Technology, 50, pp. 415-423, 2015.

25. Jol H.M., "Ground penetrating radar: theory and applications". Amsterdam: Elsevier, 2008.

326 26. Lualdi, M. and Lombardi, F., 'Combining orthogonal polarization for elongated target detection with 
27. Lualdi M. and Lombardi, F., 'Significance of GPR polarisation for improving target detection and characterisation', Nondestructive Testing and Evaluation 29(4), pp. 345-356, 2014 b.

28. Benedetto A., and Pajewski, L., 'Civil Engineering Applications of Ground Penetrating Radar', Springer International Publisher, 2015.

29. Muller, Wayne B., HabibullahBhuyan, and Alexander Scheuermann. "A comparison of modified freespace (MFS), GPR, and TDR techniques for permittivity characterisation of unbound granular pavement materials." Near Surf.Geophys. 14.6, pp. 537-550, 2016.

30. Daniels D. “Ground Penetrating Radar”, Peter Peregrinus Ltd, London, 2004.

31. MaierhoferC.,'Non destructive evaluation of concrete infrastructure with ground penetrating radar', ASCE Journal of Materials in Civil Engineering 15 (3), pp. 287-97, 2003.

32. Yehia S., Qaddoumi N., Farrag S. and Hamzeh L., 'Investigation of concrete mix variations and environmental conditions on defect detection ability using GPR', NDT\&EInt. 65, pp.35-46, 2014.

33. Sbartai Z. M., Laurens S.,Balayssac J. P., Ballivy G. and Arliguie G. 'Effect of concrete moisture on radar signal amplitude', ACI Mater Journal 103 (6), 2006a.

34. Lai W. L., Kou S. C., Tsang W. F. and Poon C. S., 'Characterization of concrete properties from dielectric properties using ground penetratingradar', Cem. and Conc. Res. 39(8), pp.687-695, 2009.

35. Laurens S., Balayssac J. P, Rhazi J. and Arliguie G., 'Influence of concrete relative humidity on the amplitude of Ground-Penetrating Radar (GPR) signal', Mat. and Struct. 35, pp. 198-203, 2002.

36. Sbartai Z. M., Laurens S., Balayssac J. P., Arliguie G. and Ballivy G., 'Ability of the direct wave of radar ground-coupled antenna for NDT of concrete structures', NDT\&E International 39 (5), pp. 400407,2006b.

38. IAEA, "Guidebook on non-destructive testing of concrete structures", International Atomic Energy Agency, 2002.

39. Xiao X., Ihamouten A.,Villain G. and Derobert X., "Use of Electromagnetic Two-layer Wave-Guided International, http://dx.doi.org/10.1016/j.ndteint.2016.08.001, 2016. 
357 40. Abraham O. and Dérobert X., "Non-destructive testing of fired tunnel walls: the Mont-Blanc Tunnel case study”, NDT\&E International 36, pp. 411-418, 2003.

359 41. Lo Monte F. and Felicetti R. "Heated slabs under biaxial compressive loading: a test set-up for the assessment of concrete sensitivity to spalling”, Materials and Structures, 2017.

361 42. EN 1991-1-2:2004, Eurocode 1 - Actions on structures - Part 1-2: General actions - Actions on structures exposed to fire, European Committee for Standardization (CEN), Brussels (Belgium), 2004.

363 43. Felicetti R., Lo Monte F. and Pimienta P. 2017. “A New Test Method to Study the Influence of Pore Pressure on Fracture Behaviour of Concrete during Heating”, Cement and Concrete Research, 94: 1323

366 44. Yilmaz Ö. Seismic data analysis: Processing, inversion, and interpretation of seismic data. Society of exploration geophysicists, 2001.

368 45. Mindeguia J. C. “ContributionExpérimental a la Compréhension des risqué d’InstabilitéThermiques des Béton", Ph.D. Thesis (in French), Université de Pau et des Pays de l'Adour, 2009. 